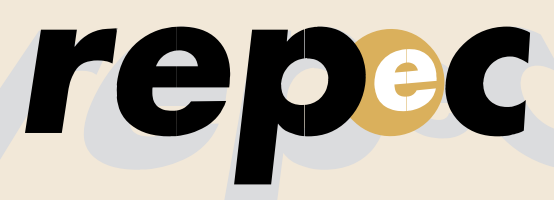

REPeC, Brasília, v. 9, n. 3, art. 1, p. 242-257, jul./set. 2015

Disponivel online em www.repec.org.br

DOI: http://dx.doi.org/10.17524/repec.v9i3.1192

\title{
A Tríade de Giddens na Pesquisa em Contabilidade
}

\section{Resumo}

Para compreender como a teoria da Estruturação foi investigada na Contabilidade, o objetivo foi analisar a Tríade de Giddens na pesquisa em Contabilidade. Realizou-se a triangulação de estudos sob o arcabouço da teoria da Estruturação (TE). Concebeu-se a dimensão estrutural da significação sob a lente perceptiva, ou seja, quando esquemas cognitivos são utilizados para interpretar a realidade. No entanto, no âmbito da informação contábil, a Contabilidade não pode ser considerada como um instrumento monolítico de interpretação das informações. Sob a lente constitutiva, têm-se as linguagens que proporcionam a construção social da realidade. Para a integração sistêmica das práticas sociais, a Contabilidade tem a função de padronização dos processos entre os diversos setores das organizações. A estrutura de legitimação a partir do dispositivo window-dressing considera a Contabilidade como um meio de refletir as expectativas da organização. No entanto, a Contabilidade precisa exercer um papel de neutralidade para conquistar a confiabilidade das informações divulgadas. A perspectiva dos dispositivos de sanção considera as avaliações das formas de interações. Assim, a partir da padronização de regras e rotinas, a Contabilidade pode promover os processos de aprovação, ou não, de condutas organizacionais. $\mathrm{Na}$ concepção da estrutura de dominação, os recursos autoritários ou alocativos promovem o exercício do poder. Desta forma, a Contabilidade pode ampliar seu campo de atuação e, como consequência, participar, diretamente, das disputas de poder nas organizações. E, por fim, trata do mecanismo ideológico que considera a Contabilidade como um mecanismo que pode facilitar a compreensão das contradições estruturais da sociedade. Para tanto, os contadores precisam ser agentes de mudanças nos processos de transformação social.

Palavras-chave: Significação; Dominação; Legitimação; Dualidade da Estrutura; Tríade de Giddens.

\section{Edson Roberto Macohon Mestre em Administração pela Universidade Regional de Blumenau - Furb e Professor Assistente B da Universidade Estadual do Centro-Oeste - Unicentro. Contato: PR 153 - KM 07 - Caixa Postal 21, Riozinho. Irati-PR. CEP.: 86300-000. \\ E-mail: ermacohon@irati.unicentro.br}

\section{Carlos Eduardo Facin Lavarda} Doutor em Contabilidade pela Universitat de Valencia, Espanha e Professor do PPGCC na Universidade Regional de Blumenau - Furb e Bolsista CNPq. Contato: Av. Antonio da Veiga, 140, Sala D-202, Victor Konder. Blumenau-SC. CEP.: 89030-903.

E-mail: elavarda@gmail.com 


\section{Introdução}

Para analisar o processo de continuidade e mudança na Contabilidade, é necessário considerar que os eventos são dependentes das circunstâncias ambientais. Assim, a Contabilidade e o contexto ao qual está inserida precisam ser investigados conjuntamente. As relações sociais reproduzidas ao longo do tempo condicionam o processo de continuidade e mudança dos artefatos da contabilidade gerencial. Nessa interação, a intencionalidade dos agentes, aqueles capazes de promover mudanças, pode facilitar ou dificultar a reprodução das práticas sociais (Burchell, Clubb \& Hopwood, 1985).

Englund, Gerdin e Burns (2011) afirmam que 25 anos atrás a teoria da Estruturação (TE) de Giddens foi introduzida na pesquisa contábil como uma reação ao enfoque histórico, apolítico e técnico-eficiência da investigação funcionalista tradicional. Atualmente, esse fluxo crescente de pesquisa aborda, aproximadamente, 65 trabalhos publicados internacionalmente. Desta forma, tornou-se uma das abordagens alternativas para explorar a Contabilidade como uma prática organizacional e social.

A mobilização da TE gerou três grandes contribuições: a introdução de uma perspectiva de dualidade (a estrutura é tanto o meio, como o resultado dos sistemas sociais); a conceituação da Contabilidade como um conjunto interligado composto de estruturas de significação, dominação e legitimação (A Tríade de Giddens); e uma base ontológica (ciência do ser) para teorizar como, quando e por que os agentes socialmente integrados podem produzir a continuidade ou a mudança das práticas contábeis (Englund, Gerdin \& Burns, 2011).

Sob a perspectiva da significação, os esquemas interpretativos são os meios cognitivos pelos quais os atores, aqueles incapazes de promover mudanças, proporcionam sentido ao que os outros dizem e fazem (Conrad, 2005). A Contabilidade, como um esquema interpretativo, tornou-se importante na organização, como é evidenciado por Conrad (2005), quando este investigou a adoção de um artefato para cumprir exigências fiscais.

Para Macintosh e Scapens (1990), sob a perspectiva da dominação, a contabilidade gerencial é um recurso que pode ser usado no exercício de poder. É um elemento-chave no processo de prestação de contas nas organizações e proporciona facilidades de mediação nas relações de poder.

Granlund (2002) afirma que a contabilidade gerencial, por meio da política e da linguagem contábil, ou seja, os relatórios financeiros, relatórios anuais, boletins informativos e diversos meios de interação e comunicação, pode ser a mediadora na busca pela legitimação organizacional.

Assim, a Tríade de Giddens pode condicionar a estruturação de artefatos da contabilidade gerencial. No entanto, pouco se sabe sobre os fatores que condicionam tal estruturação. Os estudos anteriores têm ignorado o fato de que a estruturação é um processo contínuo, pois se concentram em uma fase do ciclo de vida de implementação, ou seja, a institucionalização de hábitos e rotinas (por exemplo, Jack \& Kholeif, 2007; Jack \& Kholeif, 2008; Coad \& Herbert, 2009; Coad \& Glyptis, 2014). No entanto, pouco se sabe sobre os fatores que influenciam a estruturação no ciclo de pós-institucionalização (Hossain, Moon, Kim \& Choe, 2011).

Para tanto, a TE concebe que os agentes e estruturas não constituem dois conjuntos independentes de fenômenos (um dualismo), mas representam os dois lados da mesma moeda, por meio das estruturas de significação, dominação e legitimação. A partir deste cenário, há a promoção da continuidade dos sistemas sociais, a qual é característica fundamental de grande parte da vida social (Giddens, 2009).

No entanto, Giddens (2009) alerta que não se pode prever a ação humana, pois os atores estão sempre bem informados e reflexivos. Os agentes sabem muito sobre as condições ambientais para as práticas cotidianas e, com base nisso, podem sempre optar por fazer o contrário (Englund, Gerdin \& Burns, 2011). Assim, este problema da relação entre a ação e a estrutura social é o centro da teoria Social (Rosenbaum, 1993).

Partindo deste pressuposto, a presente pesquisa procura responder à seguinte argumentação: Como a Tríade de Giddens foi investigada na pesquisa em Contabilidade? Para tanto, o objetivo é analisar a Tríade de Giddens na pesquisa em Contabilidade. 
Para Englund, Gerdin e Burns (2011), a Tríade de Giddens permite explorar como a representação simultânea pode funcionar como um esquema interpretativo, como um facilitador para o exercício do poder e como um conjunto de normas e ideais.

Muitas abordagens críticas geralmente se concentram na capacidade de a Contabilidade refletir e reproduzir as estruturas de poder ao longo do tempo, mas muitas vezes sem uma análise aprofundada e específica das questões de significação e legitimação. No entanto, a perspectiva da TE produz um quadro útil para a compreensão de como questões simbólicas estão ligadas às questões de moralidade e de dominação, e vice-versa (Englund, Gerdin \& Burns, 2011).

Devido às poucas tentativas de teorizar holísticamente como os artefatos da contabilidade gerencial são reproduzidos no dia a dia, sugere-se a análise conjunta das três perspectivas da TE.

\section{Teoria da estruturação}

Para Giddens (2009), o estudo das práticas padronizadas e recorrentes, que se encontram estabilizadas no tempo e no espaço, é foco da pesquisa da teoria da Estruturação (TE). Os indivíduos vivem e se organizam por meio de processos dinâmicos de interação social, ou seja, todas as pessoas têm potenciais que são desenvolvidos ao longo da sua vida (Giddens, 2009). Para melhor compreensão deste cenário, a seguir, o Quadro 1 aborda as noções centrais e os aspectos-chave da TE.

\begin{tabular}{ll}
\hline \multicolumn{1}{c}{ Noçães centrais } & \multicolumn{1}{c}{ Aspectos-chave } \\
\hline $\begin{array}{l}\text { i. Estrutura e } \\
\text { sistema }\end{array}$ & $\begin{array}{l}\text { Estruturas e sistemas são tratados como conceitos distintos. Os sistemas sociais são } \\
\text { constituídos de práticas situadas, enquanto estruturas são virtuais e fora do tempo e do espaço } \\
\text { que só existem à medida que são recursivamente (processo de repetição) são envolvidos na (re) } \\
\text { produção de sistemas. }\end{array}$ \\
\hline $\begin{array}{l}\text { ii. Estrutura como } \\
\text { regras e recursos }\end{array}$ & $\begin{array}{l}\text { Estruturas podem ser analisadas como um conjunto de regras e recursos, organizados como } \\
\text { propriedades reproduzidas de sistemas sociais. }\end{array}$ \\
\hline $\begin{array}{l}\text { iii. Dualidade da } \\
\text { estrutura }\end{array}$ & $\begin{array}{l}\text { Processos de estruturação são recursivos em que a dualidade (propriedade ou caráter do que é } \\
\text { duplo ou que contém em si duas naturezas) da estrutura sugere que a estrutura funciona tanto } \\
\text { como meio para, e/ou resultados dos sistemas sociais. A dualidade da estrutura conecta, assim, } \\
\text { a reprodução de sistemas através do tempo-espaço, com a produção de interações situadas. }\end{array}$ \\
\hline $\begin{array}{l}\text { iv. Atores } \\
\text { experientes }\end{array}$ & $\begin{array}{l}\text { Agentes são tratados como experientes, que sabem muito sobre o funcionamento dos sistemas } \\
\text { sociais em virtude de sua participação em tais sistemas. Os conhecimentos que os atores se } \\
\text { apoiam na (re)produção de interação são incorporados por motivos inconscientes. }\end{array}$ \\
\hline $\begin{array}{l}\text { v. Poder como } \\
\text { elemento } \\
\text { integrante } \\
\text { da vida social }\end{array}$ & $\begin{array}{l}\text { As ações humanas são logicamente ligadas à sua capacidade de transformação, em que atores } \\
\text { podem fazer a diferença. Consequentemente, além de seu conteúdo significativo e normativo, } \\
\text { interações sociais envolvem sempre poder. }\end{array}$ \\
\hline $\begin{array}{l}\text { vi. Estruturação } \\
\text { Estruturação refere-se à repetição dos sistemas sociais, envolvendo tanto a continuidade quanto } \\
\text { a mudança. }\end{array}$ \\
\hline
\end{tabular}

Quadro 1. Noções centrais e os aspectos-chave da TE

Fonte: adaptado de Englund, Gerdin e Burns (2011).

Para Rosenbaum (1993), a estrutura torna possível a ligação de tempo-espaço dos sistemas sociais. Para tanto, tem-se a estruturação, a qual concebe a reprodução de práticas semelhantes através do tempo e do espaço. Ao contrário da estrutura, um sistema social refere-se à padronização da interação social e das relações sociais através do tempo e do espaço. A estrutura, no entanto, está presente no sistema social.

Especificamente, a estruturação refere-se às condições de continuidade ou transmutação de estruturas e, portanto, condicionam a reprodução dos sistemas sociais. A estruturação demonstra como práticas sociais e, portanto, os sistemas sociais, podem persistir em grandes períodos de tempo e espaço (Rosenbaum, 1993). O Quadro 2 explica as diferenças entre sistemas sociais e estruturas sociais. 


\begin{tabular}{|c|c|}
\hline Sistemas sociais & Estruturas sociais \\
\hline (i) Inclui as atividades atuais dos atores humanos. & $\begin{array}{l}\text { (i) As propriedades estruturais (ou seja, os modelos gerais } \\
\text { e institucionalização para a ação humana) que permitem a } \\
\text { "ligação" do espaço-tempo. }\end{array}$ \\
\hline $\begin{array}{l}\text { (ii) São sempre situados nas configurações do tempo- } \\
\text { espaço específicos. }\end{array}$ & $\begin{array}{l}\text { (ii) Estão fora do tempo e do espaço, há apenas uma } \\
\text { existência virtual. }\end{array}$ \\
\hline (iii) Estão sempre ligados a assuntos específicos. & (iii) São marcadas pela ausência de objeto. \\
\hline
\end{tabular}

Quadro 2. Diferenciação de sistemas e estruturas sociais

Fonte: adaptado de Englund, Gerdin e Burns (2011).

As estruturas podem ser divididas em um subconjunto de propriedades estruturais: (i) significação (regras); (ii) legitimação (regras); e (iii) domínio (recursos). Estruturas de significação têm o seu domínio teórico na teoria da Codificação e, por conseguinte, é necessário proporcionar regimes interpretativos para comunicação. Essas regras interpretativas fornecem meios para as pessoas interpretarem os acontecimentos. As estruturas de legitimação, por outro lado, têm o seu domínio teórico na teoria da Regulação Normativa e fornecem normas de sanção para certas formas de conduta (Englund, Gerdin \& Burns, 2011).

Para Englund, Gerdin e Burns (2011), as estruturas de dominação são concebidas pelas teorias de Autorização e Alocação de Recursos. O exercício do poder é facilitado por duas formas de recursos: (i) alocativos (por exemplo, matérias-primas, terras e tecnologia); e (ii) autoritários (por exemplo, conhecimento técnico, autoridade e competências linguísticas).

As estruturas e os sistemas são interligados de forma recursiva (repetida), por meio da dualidade da estrutura. Ou seja, essas regras e recursos que os atores se apoiam na produção e reprodução de sistemas sociais são os produtos da ação social (Englund, Gerdin \& Burns, 2011).

Para compreender o significado da dualidade da estrutura, é necessário discernir três elementos fundamentais da TE: estrutura, sistemas sociais e estruturação. A estrutura, conforme Quadro 2, é definida como as regras e os recursos que estão implicados na produção e reprodução de sistemas sociais; tem existência temporal apenas quando há ação. Neste sentido, a estrutura refere-se a uma ordem virtual de relações, fora do tempo e do espaço, que pode, quando reproduzidas em interação situada, tanto permitir como restringir a ação (Rosenbaum, 1993).

Para alcançar a ordem virtual, é necessário ter regras, que são técnicas ou procedimentos generalizáveis aplicados na promulgação e reprodução de práticas sociais (Rosenbaum, 1993). Giddens (2009) destaca que as regras mais importantes são invocadas na reprodução de práticas sociais institucionalizadas, aquelas mais profundamente sedimentadas no tempo-espaço, como também, para a ordem virtual, os recursos, que são as bases de poder para que o agente tenha acesso durante a interação social. Desta forma, como informação complementar ao Quadro 2, os recursos são propriedades estruturadas de sistemas sociais, reproduzidos por agentes com conhecimento no curso da interação (Rosenbaum, 1993).

A partir disso, concebe-se a noção da dualidade da estrutura, quando os agentes e estruturas não devem ser vistos como dois conjuntos independentes de fenômenos (um dualismo). Os sistemas, entretanto, existem apenas por meio das ações dos atores (Giddens, 2009).

Para Giddens (2009), a estruturação é a continuidade desses fenômenos, ou seja, somente as pessoas podem agir e organizar-se em coletividade. No entanto, o ator é um indivíduo proposital que está muito bem informado sobre a sua participação na produção e reprodução das práticas sociais.

Giddens (2009) concebe que as práticas sociais são consideradas a raiz da constituição do sujeito e do objeto. Assim, a estrutura conceitual da TE refuta o pensamento estruturalista da primazia da estrutura, bem como a concepção hermenêutica da ação. Para Rosenbaum (1993), Giddens descentra o ator como o sujeito e a sociedade como o objeto na estruturação dos sistemas sociais. 


\section{A teoria da estruturação na contabilidade}

O arcabouço da teoria da Estruturação (TE) induz à interpretação holística da Contabilidade como estruturas de significação, legitimação e dominação. Na sequência, o Quadro 3 apresenta os estudos internacionais que contemplam as dimensões estruturais da Contabilidade sob a perspectiva da TE.

\begin{tabular}{|c|c|c|}
\hline Dimensões estruturais & Aspectos chaves dos estudos & Referências \\
\hline \multicolumn{3}{|l|}{$\begin{array}{l}\text { 1. Contabilidade como } \\
\text { estrutura de significação }\end{array}$} \\
\hline Lente perceptiva & $\begin{array}{l}\text { Contabilidade é modelada como esquema cognitivo } \\
\text { para interpretar a realidade. }\end{array}$ & $\begin{array}{l}\text { Boland (1993); Jack (2005); Scapens e } \\
\text { Macintosh (1996) }\end{array}$ \\
\hline Lente constitutiva & $\begin{array}{l}\text { Contabilidade é modelada como uma linguagem } \\
\text { por meio da qual a realidade é construída } \\
\text { socialmente. }\end{array}$ & $\begin{array}{l}\text { Macintosh e Scapens (1990); Roberts } \\
\text { (1990) }\end{array}$ \\
\hline \multicolumn{3}{|l|}{$\begin{array}{l}\text { 2. Contabilidade como } \\
\text { estrutura de legitimação }\end{array}$} \\
\hline $\begin{array}{l}\text { Dispositivo } \\
\text { Window-dressing }\end{array}$ & $\begin{array}{l}\text { Contabilidade é modelada como um meio de refletir } \\
\text { as expectativas da organização e da sociedade. }\end{array}$ & $\begin{array}{l}\text { Granlund (2002); Granlund, Lukka e } \\
\text { Mouritsen (1998); Lawrenson (1992) }\end{array}$ \\
\hline Dispositivo de sanção & $\begin{array}{l}\text { Contabilidade é modelada como um meio de } \\
\text { sanção de certas formas de (inter)ações. }\end{array}$ & $\begin{array}{l}\text { Conrad (2005); Lawrence et al. (1997); } \\
\text { Macintosh (1995) }\end{array}$ \\
\hline \multicolumn{3}{|l|}{$\begin{array}{l}\text { 3. Contabilidade como } \\
\text { estrutura de dominação }\end{array}$} \\
\hline $\begin{array}{l}\text { Recursos para } \\
\text { dominação }\end{array}$ & $\begin{array}{l}\text { Contabilidade é modelada como um recurso que } \\
\text { pode ser utilizado no exercício do poder. }\end{array}$ & $\begin{array}{l}\text { Collier (2001); Cowton e Dopson } \\
\text { (2002); Jack (2007); Saravanamuthu e } \\
\text { Tinker (2003); Uddin e Tsamenyi (2005) }\end{array}$ \\
\hline Mecanismo ideológico & $\begin{array}{l}\text { Contabilidade é modelada como um } \\
\text { mecanismo ideológico, o qual está incorporado } \\
\text { constitutivamente nas relações sociais }\end{array}$ & $\begin{array}{l}\text { Alam et al. (2004); Jayasinghe e } \\
\text { Thomas (2009); Jones e Dugdale (2001) }\end{array}$ \\
\hline
\end{tabular}

Quadro 3. Dimensões estruturais da contabilidade sob a perspectiva da TE (estudos internacionais)

Fonte: adaptado de Englund, Gerdin e Burns (2011).

O Quadro 4 apresenta os estudos nacionais que concebem as dimensões estruturais sob a perspectiva da TE.

\begin{tabular}{ll}
\hline \multicolumn{1}{c}{ Dimensões estruturais } & \multicolumn{1}{c}{ Referências } \\
\hline 1. Estrutura de significação & \\
\hline Lente perceptiva & Guarido Filho e Costa (2012); Santos (2008); Tavares (2012) \\
\hline Lente constitutiva & Wanderley e Cullen (2012) \\
\hline 2. Estrutura de dominação & \\
\hline Recursos para dominação & $\begin{array}{l}\text { Rodrigues (2008); Silva e Fonseca (1993); Ribeiro (2010); Beuren e Almeida (2012); } \\
\text { Cosenza, Teixeira Filho e Lopes (2012); Walter, Cruz, Espejo e Gassner (2009) }\end{array}$ \\
\hline
\end{tabular}

Quadro 4. Dimensões estruturais sob a perspectiva da TE (estudos nacionais)

Fonte: dados da pesquisa.

Devido aos poucos estudos nacionais sobre o enfoque da TE na Contabilidade, utilizaram-se também estudos que abordaram outras áreas organizacionais. Percebe-se que não há estudos com enfoque na estrutura da legitimação, como também, na estrutura de dominação, não há estudos sobre mecanismo ideológico.

Os próximos capítulos estão organizados a partir da triangulação dos estudos dentro das perspectivas de significação, legitimação e dominação, conforme apresentação dos Quadros 3 e 4 . 


\subsection{Contabilidade como estrutura de significação}

\subsubsection{Lente perceptiva}

A teoria da Estruturação (TE), de Anthony Giddens, foi empregada por Macintosh e Scapens (1990), os quais argumentaram que os sistemas de contabilidade gerencial são normas e esquemas interpretativos utilizados por gerentes para fazer planos, tomar decisões e para controlar outras pessoas nas organizações (Boland, 1993).

Giddens (2009) define esquemas interpretativos assim como os modos de tipificação incorporados pelos atores são estoques de conhecimento. Jack (2005) exemplifica, a partir de Berger e Luckmann (1990), que os estoques de conhecimento de uma sociedade são estruturados em termos do que é, geralmente, relevante para funções específicas. Geralmente, o conhecimento relevante diz respeito aos fatos reconhecidos, métodos e procedimentos. O conhecimento específico é mais concreto. Por exemplo, um contador deve saber sobre as técnicas contábeis Generally Accepted Accounting Principles (GAAP), bem como sobre normas, valores e emoções adequadas para o papel de especialista. O conhecimento é, portanto, socialmente distribuído e, além disso, pode-se supor que o conhecimento específico crescerá a um ritmo mais rápido do que o conhecimento em geral, relevante e acessível (Jack, 2005).

Na concepção de Gadamer (1976), Boland (1993) destaca que as ações dos atores, por meio dos sistemas de contabilidade gerencial, podem mediar o processo interpretativo, mas podem fazê-lo de maneiras surpreendentes e inesperadas. $\mathrm{O}$ ato interpretativo é uma condição universal do estar no mundo. $\mathrm{O}$ significado das ações dos indivíduos é uma interpretação e, não, algo que é simplesmente concebido. A criação de significados por meio da interpretação é uma realização qualificada do indivíduo (Giddens, 2009).

De acordo com Giddens (2009), o ser humano é um agente intencional ao reconhecer que os agentes usam suas habilidades linguísticas para falar, escrever e refletir sobre as regras e os recursos utilizados na interação social. $\mathrm{O}$ ato interpretativo pode resultar em múltiplos e equívocos significados. Os indivíduos não são bobos sociais, mas seres existenciais que reflexivamente monitoram as lógicas do fluxo contínuo da vida social. Isto está em contraste direto com o ponto de vista estruturalista, a partir do qual os agentes estão implicitamente vistos como ingênuos sociais (Scapens \& Macintosh, 1996).

Quanto ao papel dos atores sociais no contexto da Contabilidade, o estudo de Guarido .Filho e Costa (2012, p. 01) indica quatro implicações analíticas: "a natureza social das práticas contábeis; o reconhecimento da dimensão sociocultural subjacente ao ambiente contábil; a interposição entre legalidade e legitimidade das práticas contábeis; e o entendimento da profissão enquanto ator social relevante na construção do ambiente contábil”.

Dessa forma, os contadores fazem leituras interpretativas de uma situação organizacional como base para fazer registros e relatórios. Os relatórios contábeis, por sua vez, são interpretados pelos gestores para tentar compreender situações organizacionais (Boland, 1993).

A partir de Cohen (1989), Scapens e Macintosh (1996) concebem que, na perspectiva da contabilidade gerencial, a TE fornece aos pesquisadores uma estrutura teórica que pode ser base para estudar a contabilidade gerencial como parte das rotinas estabelecidas e condutas institucionalizadas. Na TE, os agentes com consciência prática dos padrões adequados de comportamento mantêm esses padrões por meio de sua participação ativa em rotinas institucionalizadas.

A TE é uma abordagem para a compreensão do mundo social, que substitui os dualismos tradicionais da teoria Social, a qual retrata a estrutura social como algo que existe independente da ação humana (Giddens, 2009). No lugar destes dualismos com perspectivas separadas, Giddens (2009) apresenta a dualidade da estrutura, em que a estrutura é tanto o meio quanto o resultado da reprodução de práticas.

A TE de Giddens é, portanto, uma teoria hermenêutica, na medida em que enfatiza o esforço contínuo do ator, no sentido de decisões, como a instanciação da estrutura social. Se visto como meio ou como resultado, a estrutura está presente apenas durante a hermenêutica, ou seja, o ato interpretativo (Boland, 1993). 
Jack (2005) corrobora Scott (2001) sobre o uso da TE, a qual permite que a instituição seja examinada em termos de processos. Em vez de propriedades, as estruturas são reproduzidas por atores. Trata-se, como o próprio Giddens (2009) reivindica, de um dispositivo sensibilizador, em vez de uma estrutura universal (Jack, 2005). O estudo de Jack (2005) analisa as estruturas de outra perspectiva, a partir do processo cognitivo. Neste contexto, a autora examina o início da difusão e rotinização da técnica contábil intitulada "margem bruta" e procura entender por que esta prática ainda persiste, embora de uma forma simplificada e não intencional.

No contexto de mudança, os resultados de Santos (2008) contradizem os estudos anteriormente mencionados, pois em sua pesquisa constatou que o ambiente legal, normativo e cultural cognitivo não promoveu mudanças profundas nas práticas da contabilidade gerencial nas indústrias do setor elétrico brasileiro. No entanto, Tavares (2012) revelou que a assimilação de sistemas de informação no setor bancário foi influenciada pela confluência de objetivos individuais e organizacionais e pelo tipo de treinamento aplicado.

Giddens distingue três modalidades de estruturação, ou três dimensões das regras e recursos nos quais os atores apoiam e instituem o ato interpretativo, nos quais se incluem os esquemas interpretativos; as normas, ou seja, a atualização dos direitos e promulgação de obrigações; e a reprodução das relações de autonomia e dependência na interação social (Boland, 1993).

Visto como práticas institucionalizadas, os esquemas interpretativos dão origem aos modos de significação; às normas, aos modos de legitimação e, assim, por meio da recursividade das relações sociais, às formas de dominação. Como aponta Giddens, estas modalidades não são fenômenos isoláveis, mas se cruzam com as dimensões da totalidade das práticas sociais institucionalizadas. $\mathrm{O}$ ato interpretativo invoca o entendimento de todas as três dimensões que se reproduzem na ação. Qualquer ato de interpretação baseia-se em entendimentos pessoais (Boland, 1993).

Giddens (2009) destaca que as estruturas de significação sempre têm que ser compreendidas por meio da conexão com a dominação e legitimação. Um dos princípios básicos enunciado pelo autor afirma que a cognoscitividade dos atores é sempre limitada, por um lado pelo inconsciente e, por outro, pelas condições não reconhecidas, consequências não intencionais. As atividades sociais são encenadas por meio da ação intencional que leva a consequências não intencionais (Jack, 2005).

Em resposta a Boland (1993), Scapens e Macintosh (1996) afirmam que Giddens oferece um conjunto bilateral de suportes e faz uma distinção entre análise institucional e análise da conduta estratégica. Scapens e Macintosh (1996) destacam que esta distinção pode acomodar a visão deles como a de Boland na TE. A diferença é que a análise institucional centra-se no entrelaçamento das regras e recursos dos sistemas sociais, enquanto a análise da conduta estratégica concentra-se sobre como os atores recorrem a essas regras e recursos na constituição de sua interação (Scapens \& Macintosh, 1996).

\subsubsection{Lente constitutiva}

Quando analisou o funcionamento dos sistemas de prestação de contas, Giddens inspirou-se na formulação da teoria da Dualidade da Estrutura, que explora a interação dos três elementos fundamentais, a sua constituição como significado, a sua constituição como uma ordem moral e a sua constituição como o funcionamento das relações de poder (Roberts, 1990).

Para Giddens (2009), ação e estrutura não são opostas, complementam-se de forma recursiva. A ordem virtual das estruturas de significação, legitimação e dominação é desenhada a partir da interação de indivíduos e estruturas. Na Contabilidade, a estrutura de significação é desenhada por meio de significados dos eventos organizacionais, como, por exemplo, práticas rotineiras de prestação de contas. Ao mesmo tempo, essas práticas promulgam e impõem determinados direitos e obrigações das relações de poder, contribuindo, assim, para a reprodução de estruturas mais amplas de legitimação e dominação (Roberts, 1990). Desta forma, a Contabilidade é modelada como uma linguagem pela qual a realidade é construída socialmente (Englund, Gerdin \& Burns, 2011). 
Roberts (1990) não está preocupado com os padrões visíveis de relações, mas, sim, com a sua produção e reprodução ao longo do tempo, a construção da realidade. Em comparação com as discussões convencionais de estrutura, tal ponto de vista de estruturação é mais abrangente, em que a discussão não se limita ou falsamente separa as estruturas internas das organizações ou de mercados. Para tanto, deve-se considerar as implicações desta análise para a compreensão do papel da Contabilidade e sua relação com a estratégia (Roberts, 1990).

A teoria da Estruturação (TE) pode ser útil na tentativa de entender o contexto social da contabilidade gerencial nas organizações. A TE está preocupada com a compreensão da relação entre as atividades dos atores e a estruturação dos sistemas sociais (Giddens, 2009).

Ao analisar sistemas sociais, Giddens (2009) distingue entre sistema e estrutura. Para os sistemas sociais, o autor considera as práticas sociais perceptivelmente similares àquelas que são reproduzidas através do tempo e do espaço por meio das ações dos agentes, enquanto as estruturas são as propriedades estruturantes que fornecem a ligação destas práticas sociais aos sistemas sociais. Para enfatizar esta distinção, pode-se afirmar que os sistemas não são estruturas, mas sim que os sistemas têm estruturas que são desenhadas em cima da interação social. Assim, no contexto da Contabilidade, os sistemas contábeis gerenciais estão implicados na construção, manutenção e alterações da ordem social de uma organização (Macintosh \& Scapens, 1990).

No que diz respeito às mudanças nas práticas contábeis gerenciais, Wanderley e Cullen (2012) constataram que o controle orçamentário e o sistema de medida de desempenho foram institucionalizados em uma indústria elétrica regulada no Brasil. Os autores revelaram, ainda, que as estruturas de significação, legitimação e dominação, nos níveis político e econômico, proporcionaram o contexto social, político e econômico, que refletiram nas mudanças da contabilidade gerencial. Os sistemas contábeis foram instrumentos essenciais para construir a nova estratégia de negócios da indústria em estudo (Wanderley \& Cullen, 2012).

\subsection{Contabilidade como estrutura de legitimação}

\subsubsection{Dispositivo Window-Dressing}

Granlund (2002) confere a Luhmann (1979) e Barber (1983) a afirmação de que os sociólogos têm considerado, por muito tempo, a confiança como uma parte integrante da interação social que torna a vida social possível. As pessoas precisam ganhar legitimação de suas ações e também têm que ser capazes de confiar nas ações dos outros. A contabilidade, a legitimidade e a confiança são, portanto, ingredientes interligados e necessários ao fluxo da vida humana (Granlund, 2002).

Os sistemas de informação são utilizados nas estruturas de dominação e legitimação na busca pela confiança (Giddens, 2009). Com o tempo, os sistemas de informação tornam-se cada vez mais importantes como mediadores da confiança organizacional (Granlund, 2002).

Roberts (1990) sugere que os artefatos da contabilidade refletem e, em parte, resolvem o problema da confiança e da divergência de interesses. A Contabilidade é mobilizada como uma instituição de legitimação não apenas nos relatórios financeiros das empresas, mas também em relatórios anuais, boletins informativos e meios de comunicação (Granlund, 2002).

O estudo de Lawrenson (1992) revela que o avanço da contabilidade em uma indústria ferroviária do Reino Unido foi um fator que contribuiu para a mudança de atitude de engenheiros. O desenvolvimento da Contabilidade representou um meio para refletir as expectativas da organização e da sociedade, o qual foi percebido como uma ameaça para o domínio da profissão dos engenheiros no setor ferroviário. Em resposta ao desenvolvimento da contabilidade gerencial, os engenheiros começaram a entender as novas rotinas e conceitos contábeis e a procurar meios que não poderiam ser adotados pelos contadores. Os engenheiros, portanto, dirigiram a sua atenção para os processos físicos de produção, que até então haviam sido negligenciados pelos contadores e eram de conhecimento exclusivo dos funcionários do setor operacional de produção, o que permitiu que os engenheiros se mantivessem no poder (Lawrenson; 1992). 
Devido à abertura de mercado na União, uma empresa finlandesa do setor de alimentos passou pelo processo de reestruturação organizacional. Este fenômeno foi analisado por Granlund (2002), que descobriu que a organização passou a agir de acordo com o estabelecimento da nova ordem de legitimação. A gestão corporativa começou a convencer o pessoal da nova direção à criação de uma nova estratégia. Esse processo de reengenharia e a mudança da contabilidade gerencial passaram a ser componentes importantes de uma nova ideologia operacional, implicando, também, em uma nova cultura corporativa (Granlund, 2002).

A pesquisa de Granlund et al. (1998) demonstrou que as questões macroambientais, como, por exemplo, a internacionalização, a globalização e o Bloco da União Europeia, em particular, são elementos de legitimação em relatórios contábeis das indústrias de alimentos na Finlândia. Os autores revelaram uma conexão entre o debate social mais amplo e as preocupações das empresas. Assim, são capazes de fazer alinhamentos importantes, que, por sua vez, facilitam as reestruturações societárias.

\subsubsection{Dispositivo de sanção}

As estruturas de legitimação são constituídas pelas regras e obrigações morais de um sistema social. Assim, constituem o conjunto compartilhado de valores e ideais sobre o que é importante e o que deve acontecer nos ambientes sociais (Macintosh, 1994). Por conseguinte, as estruturas de legitimação podem ser vistas como a sanção de valores e ideais comunicados por regimes regulamentares (Conrad, 2005).

O estudo de Lawrence et al. (1997) analisa a evolução de novas instituições de saúde da Nova Zelândia e, em particular, os pontos nos quais as práticas contábeis e os profissionais médicos se contrapõem. Os autores trataram a Contabilidade como parte de práticas sociais mais amplas, utilizaram a teoria da Estruturação (TE) de Giddens para compreender as maneiras pelas quais os contadores e suas práticas estão implicadas em determinadas reformas sociais. Cada vez mais, há uma aceitação de que a Contabilidade não pode ser entendida como uma esfera autônoma da atividade, mas deve ser vista como parte de uma série complexa de contextos político, econômico e organizacional (Lawrence et al., 1997).

A partir deste contexto organizacional, Conrad (2005) destaca que sistemas de prestação de contas fornecem uma estrutura de significados para a interação social, ou seja, a estrutura de significação, como também incorporam uma ordem moral, a estrutura de legitimação, uma vez que definem os direitos e obrigações (Macintosh, 1995; Conrad, 2005).

Macintosh (1995) afirma, ainda, que os artefatos da contabilidade gerencial comunicam um conjunto de valores e ideais sobre o que é aprovado ou não, bem como as políticas de recompensas e penalidades. Assim, tais artefatos tornam-se um importante meio de sanção das ações dos gestores (Macintosh, 1995).

Lawrence et al. (1997) constataram, no setor de saúde neozelandês, que as informações da contabilidade estavam se tornando cada vez mais importantes e aceitas como uma significativa modalidade interpretativa. O obstáculo sociopolítico foi superado e os artefatos da contabilidade passaram a ser utilizados como mecanismos de sanção, por meio de novas relações de prestação de contas (Lawrence et al., 1997).

Giddens (2009) associa, explicitamente, o aspecto sancionatório da moralidade com o lado opressor e aquiescência das relações de poder. Tal análise pode identificar como os artefatos da contabilidade tornam-se mecanismos de conflitos e disputas de poder dentro da perspectiva da dialética de controle. Assim, o arcabouço da TE pode conceber explicações do comportamento, moralmente adequado, da contabilidade nos papéis sociais e políticos das organizações (Macintosh, 1995). 


\subsection{Contabilidade como estrutura de dominação}

\subsubsection{Recursos para dominação}

Na concepção de Lowe, Puxty e Chua (1989), Cowton e Dopson (2002) afirmam que os últimos anos testemunharam o desenvolvimento de perspectivas mais críticas sobre o controle gerencial que abordam, explicitamente, as questões de poder. A partir de Hoskin (1998), Cowton e Dopson (2002), recomendam o pensamento de Michel Foucault, o qual reconhece o movimento do poder nas organizações e na sociedade. Embora Foucault tenha escrito praticamente nada sobre gestão ou contabilidade, passou a ter uma grande influência nestas áreas. O objetivo do estudo de Cowton e Dopson (2002) foi avaliar, por meio da apresentação e discussão de um estudo de caso, o valor da perspectiva foucaultiana emergente para o estudo do controle gerencial.

Weber (1947) define o poder como a probabilidade de que um ator, dentro de uma relação social, é capaz de realizar a sua própria vontade, apesar da resistência. Mais recentemente, Pfeffer (1992) definiu o poder como a capacidade de influenciar o comportamento e superar a resistência. Essas definições de poder incorporam, explicitamente, conflito e resistência. Clegg (1979) argumentou que o poder deriva do controle dos meios e dos métodos de produção (Collier, 2001).

Em contraste com as interpretações convencionais do processo civilizatório, Foucault argumenta que o conhecimento é produzido pelo discurso e entende o conhecimento como necessário para examinar as instituições que o produzem. Foucault desenvolve a noção de práticas que servem para criar não só o conhecimento, mas também o poder. O poder e conhecimento são, portanto, para Foucault, dois lados de uma mesma relação social, dando origem ao conceito de poder e conhecimento (Cowton \& Dopson, 2002).

Scapens e Roberts (1993) utilizaram a teoria da Estruturação (TE) para distinguir as concepções de poder e assim focar as tensões sobre o uso da Contabilidade, tanto como um dispositivo de habilitação quanto para alcançar o controle hierárquico. Scapens e Roberts (1993) empregam uma perspectiva foucaultiana de que os efeitos do poder não são negativos, mas produtivos (Collier, 2001). Para Silva e Fonseca (1993, p. 22) "o poder e o comprometimento são fatores determinantes na intensidade da mudança, devido à luta empreendida entre os diversos grupos ou agentes organizacionais para protegerem seus interesses na delimitação da configuração estrutural".

O conceito de poder e conhecimento de Foucault é elaborado com alguma profundidade na obra Vigiar e Punir, em que Foucault considera as mudanças que ocorreram nos mecanismos de punição na Europa nos séculos XVIII e XIX. Foucault argumenta que, no espaço de 80 anos ou mais, desapareceu o método de punição por meio da tortura, para ser substituído por um sistema generalizado e impessoal de vigilância que concentrou a atenção sobre a psicologia do indivíduo (Cowton \& Dopson, 2002).

A partir da psicologia organizacional e o ambiente normativo da contabilidade, Cosenza, Teixeira Filho e Lopes (2012, p. 81) destacam as práticas de poder da contabilidade:

As práticas de poder nas relações interpessoais e interorganizacionais, como as habilidades em agrupar informações contábeis e transformá-las em relatórios gerenciais, e o poder oriundo do enforcement das instâncias colegiadas de organismos reguladores das práticas e atividades contábeis no Brasil.

Giddens (2009) expressa um considerável grau de admiração pela obra de Foucault, mas não considera como uma contribuição para o projeto de uma teoria social geral. Afirma a importância da vigilância, mas apenas como um dos quatro principais aspectos institucionais da modernidade, juntamente com o capitalismo, o industrialismo e o poder militar (Cowton \& Dopson, 2002).

A principal dificuldade de Giddens na bagagem filosófica de Foucault é a não consideração do conhecimento da agência. Uma das características importantes da abordagem da estruturação de Giddens é que, apesar de reconhecer a maneira em que contexto influencia o comportamento, por meio de recursos, há a possibilidade de ação individual dos atores (Cowton \& Dopson, 2002). Walter et al. (2009), sob a perspectiva de Giddens, afirmam que o poder de agência condiciona as ações organizacionais nos níveis micro e macro da organização. 
Na análise de Giddens (2009) sobre poder, está implícita a dominação, a qual é percebida como um produto de controle sobre os recursos (Uddin \& Tsamenyi, 2005). Para Ribeiro (2010, p. 6), "Conceitualmente, o controle está intimamente associado ao exercício do poder". Isso dá a certos indivíduos ou grupos, eventualmente, a percepção de poder nas relações sociais.

Giddens (2009) distingue dois tipos de recursos, alocativos e autoritários, e define estes recursos da seguinte forma: a) recursos alocativos: recursos materiais envolvidos na geração de energia, incluindo o meio ambiente natural e artefatos físicos, derivam do domínio humano sobre a natureza; e b) recursos autoritários: recursos não materiais envolvidos na geração de energia, decorrente da capacidade de aproveitar as atividades dos seres humanos, são o resultado do domínio de alguns atores em detrimento de outros.

Por conseguinte, na visão de Foucault e Giddens, os recursos promovem facilidades nas relações sociais: "As facilidades representam os meios que os atores utilizam para atingir seus objetivos e alcançar os resultados, por meio dessas facilidades surge o poder" (Beuren \& Almeida, 2012, p. 656). Na visão de Giddens, os recursos são os meios por meio dos quais o poder é exercido. Como resultado, tem uma influência limitada na sociedade pela quantidade disponível de recursos (Uddin \& Tsamenyi, 2005).

Jack (2007) investigou as mudanças de assimetrias de poder no setor agrícola do Reino Unido. A pesquisa abrangeu os agricultores, Governo, serviços de extensão rural, bem como as corporações. Sob a perspectiva da dominação, elucidou as dificuldades enfrentadas pelos agricultores, bem como o entendimento das estratégias para o desenvolvimento da contabilidade gerencial no setor agrícola.

As estratégias de gestão são influenciadas pelas formas de tecnologia, habilidades dos trabalhadores e concorrência. No entanto, essas estratégias podem ser afetadas pela capacidade de resistência dos trabalhadores. Para tanto, as organizações desenvolvem políticas de dialética do controle (Saravanamuthu \& Tinker, 2003).

A dialética de controle indica como práticas organizacionais moldam e são moldadas pela complexa relação de poder entre subordinados e superiores em vários níveis de estrutura de poder, dentro e fora da organização (Giddens, 2009). O foco central da TE, na análise do poder, é a dialética do controle, o que explica o poder em duas vias. Assim, nas relações de poder, não há condição em que uma das partes possui poder absoluto, enquanto o outro possui nenhum poder (Uddin \& Tsamenyi, 2005).

O trabalho de Uddin e Tsamenyi (2005) baseia-se na dialética de controle para explorar a forma como o orçamento atua no setor público em países menos desenvolvidos. Esse aspecto de estruturação oferece um caminho para examinar como diferentes órgãos estatais e agentes interagem para moldar as práticas atuais de controle gerencial e orçamento nas empresas estatais de Gana.

Poder e resistência estão presentes em todo o processo de interação entre o usuário e o sistema, bem como nas transformações sobre o trabalho (Rodrigues, 2008). A Contabilidade é o principal meio de monitoramento das ações da gestão - é oficial, embora seja uma norma de gestão contestada. A Contabilidade deve ter ambas as dimensões (morais e instrumentais) de poder, porque influencia a forma como a gestão navega por meio das contradições entre capital e trabalho (Saravanamuthu \& Tinker, 2003).

\subsubsection{Mecanismo ideológico}

Nos últimos anos, a Contabilidade passou a ser vista como uma prática social e institucional que atua sobre as pessoas, entidades e processos. Além disso, essa prática é vista como uma das entidades mais influentes de especialização em muitas sociedades ocidentais, tornando-se um elemento central de governo, como um mecanismo de gestão social e econômico. Nesse processo, os contadores têm ocupado posições poderosas nas organizações empresariais. Em suma, a Contabilidade é influenciadora tanto do indivíduo, como da sociedade (Jones \& Dugdale, 2001). 
O estudo de Jayasinghe e Thomas (2009) explora como e por que as antigas práticas da contabilidade foram preservadas em uma comunidade rural subalterna no Sri Lanka, apesar das pressões externas para a mudança. Em particular, examina como estas práticas contábeis são mobilizadas no cotidiano da comunidade e como e por que, os membros da comunidade tendem a preservá-las de geração em geração (Jayasinghe \& Thomas, 2009).

Há duas questões importantes de análise da Contabilidade como um mecanismo de poder. A primeira diz respeito à construção da Contabilidade como uma rede de práticas. Cada prática individual está relacionada a grupos de outras práticas contábeis, que estão embutidas nos conhecimentos da Contabilidade como uma forma de discurso econômico. O poder da Contabilidade pode, portanto, residir, não em qualquer prática específica, mas na interligação da rede de práticas. A segunda questão é a Contabilidade ser incorporada e constituir as relações sociais para identificar o seu poder. Desta forma, não são consideradas somente as práticas e as informações geradas, mas também a sua permeabilidade nas relações sociais e nas formas de pensar (Jones \& Dugdale, 2001).

Alam et al. (2004) inspiraram-se em Benson (1977) e Neimark e Tinker (1986) para afirmarem que a ordem social e organizacional é produzida e reproduzida por meio do processo de construção social ao longo do tempo e do espaço e pode conter contradições, rupturas, inconsistências e incompatibilidades, como parte do próprio tecido da vida social.

A Contabilidade é um instrumento utilizado para minimizar tais contradições. Essa visão enfatiza como as práticas contábeis envolvem o funcionamento das relações de poder ou de um sistema de dominação por meio de mecanismos de prestação de contas (Jayasinghe \& Thomas, 2009).

Os fundamentos teóricos do estudo de Alam et al. (2004) baseiam-se na noção das contradições, um tema importante na teoria da Estruturação (TE) de Giddens. A abordagem é a tradição de pensar dialeticamente, ou seja, não olhar para as funções das práticas sociais, mas procurar as suas contradições. A contradição é um elemento-chave da visão dialética marxista da vida social e organizacional (Alam et al., 2004).

Neste sentido, Alam et al. (2004) investigaram as mudanças nas operações e práticas contábeis no Banco de Desenvolvimento de Fiji. O estudo constatou que o lucro está em desacordo com a cultura local. A tradição local é contraditória com o desenvolvimento capitalista. A decisão do banco de aumentar a lucratividade, por meio de uma tecnologia baseada no lucro, foi contraditória com o seu papel tradicional de desenvolvimento em Fiji (Alam et al., 2004).

A análise da contabilidade como um mecanismo ideológico induz a reflexões acerca do seu papel na constituição das relações sociais. Para tanto, é necessário o envolvimento ativo dos contadores nos processos de transformação social.

\section{Considerações finais}

A estrutura de significação, sob a lente perceptiva, concebe a Contabilidade como um esquema cognitivo, com objetivo de interpretar a realidade. No entanto, os artefatos da Contabilidade não podem ser considerados instrumentos monolíticos da informação. Conforme preconiza Giddens (2009), os atores são propositais e intencionais nas suas condutas. Desta forma, o ato interpretativo é concebido pelos indivíduos, neste caso, os usuários das informações contábeis. As informações extraídas por meio dos relatórios contábeis dependem do contexto de cada usuário. Assim, a interpretação destas informações transcende as fronteiras do conhecimento contábil.

A partir disso, concluiu-se que os estudos de Boland (1993); Jack (2005); Scapens e Macintosh (1996); Guarido Filho e Costa (2012); Santos (2008); e Tavares (2012) promoveram uma incursão quanto aos seguintes quesitos-chave da teoria da Estruturação (TE): a) esquemas interpretativos; b) estoques de conhecimento; c) intencionalidade dos agentes; d) condutas institucionalizadas; e) dualidade da estrutura; f) processo cognitivo; g) difusão e rotinização; h) assimilação de sistemas; i) interação social; e j) análise da conduta estratégica. 
A estrutura de significação, sob a lente constitutiva, analisa a Contabilidade como uma linguagem por meio da qual a realidade é construída socialmente. Assim, para a integração sistêmica das práticas sociais, a Contabilidade tem a função de padronização dos processos entre os diversos setores das organizações. Desta forma, as pesquisas de Macintosh e Scapens (1990), Roberts (1990) e Wanderley e Cullen (2012) revelaram os seguintes aspectos-chave: a) sistemas de prestação de contas; b) dualidade da estrutura; e c) estratégia organizacional.

A estrutura de legitimação, no âmbito do dispositivo window-dressing preconiza a Contabilidade como um meio para refletir as expectativas da organização e da sociedade. Dessa forma, a Contabilidade precisa exercer um papel de neutralidade para conquistar a confiabilidade das informações divulgadas pelas empresas. As pesquisas de Granlund (2002), Granlund et al. (1998) e Lawrenson (1992) destacaram os referidos aspectos: a) confiança; b) expectativas da organização; e c) eventos macroeconômicos.

A estrutura de legitimação, na perspectiva dos dispositivos de sanção, concebe a Contabilidade como um meio de sanção das relações sociais. A partir da padronização de regras e rotinas, a Contabilidade pode promover os processos de aprovação, ou não, de condutas organizacionais. Nesse sentido, Conrad (2005), Lawrence et al. (1997) e Macintosh (1995) investigaram os seguintes aspectos-chave: a) regras e obrigações morais; b) constituição moral de ações e interações dos gestores; c) prestação de contas; e d) dialética de controle.

A estrutura de dominação, na forma de recursos para dominação, analisa a Contabilidade como um recurso que pode ser autoritário no exercício do poder. A partir da integração sistêmica nas organizações, a Contabilidade pode ampliar seu campo de atuação, e, como consequência, participar diretamente das disputas de poder.

Essa perspectiva foi investigada por Collier (2001); Cowton e Dopson (2002); Jack (2007); Saravanamuthu e Tinker (2003); Uddin e Tsamenyi (2005); Rodrigues (2008); Silva e Fonseca (1993); Ribeiro (2010); Beuren e Almeida (2012); Cosenza, Teixeira Filho e Lopes (2012); e Walter et al. (2009), que destacam o seguinte: a) poder; b) controle gerencial; c) conflito e resistência; d) conceito de poder e conhecimento; e) poder e comprometimento; f) psicologia do indivíduo e organizacional; g) ambiente normativo; h) relações interpessoais e interorganizacionais; i) vigilância; j) conhecimento da agência; k) recursos alocativos e autoritários; 1) poder de agência; $m$ ) assimetrias do poder; n) dialética do controle; e o) dualidade da estrutura.

A estrutura de dominação, sob a perspectiva de mecanismo ideológico, considera a Contabilidade como um mecanismo que pode facilitar a compreensão das contradições estruturais da sociedade. Para tanto, os contadores precisam ser agentes de mudanças nos processos de transformação social.

Nesta perspectiva, Alam et al. (2004); Jayasinghe e Thomas (2009); e Jones e Dugdale (2001) destacaram os seguintes pontos: a) mecanismos de gestão social e econômico; b) manutenção de práticas sociais; c) rede de práticas sociais; d) relações sociais e poder; e) contradições, rupturas, inconsistências e incompatibilidades da vida social; f) sistemas de dominação; e g) dialética do controle.

Para pesquisas futuras, sob o arcabouço teórico interpretativista e qualitativo da TE de Giddens, na concepção da meta estrutura de significação, sugere-se a investigação das funções, atividades e comunicação da contabilidade gerencial e/ou controladoria no contexto estratégico empresarial. Quanto à meta estrutura de legitimação, sugere-se verificar as obrigações, mecanismos de sanção, comportamentos legitimados e produção de moralidade da contabilidade e/ou controladoria em relação a outros setores da organização. Por último, quanto à meta estrutura de dominação, recomenda-se pesquisas acerca de recursos autoritários, recursos alocativos, facilidades, relações sociais e poder, no contexto da contabilidade e/ ou controladoria em ambientes integrados de gestão. 


\section{Referências}

Alam, M., Lawrence, S., \& Nandan, R. (2004). Accounting for economic development in the context of post-colonialism: the Fijian experience. Critical Perspectives on Accounting, 15(1), pp. 135-157.

Barber, B. (1983). The logic and limits of trust. New Brunswick, NJ: Rutgers University Press. DOI: 10.5840/ bpej1983237

Benson, J. K. (1977). Organizations: A Dialectical View. Administrative Science Quarterly. 22(1), pp. 1-21. DOI: $10.2307 / 2391741$

Berger, P. L., \& Luckmann, T. (1990). Tafsir Sosial atas Kenyataan. LP3ES, Jakarta.

Beuren, I. M., \& Almeida, D. M. (2012). Impactos da implantação das normas internacionais de contabilidade na controladoria: um estudo à luz da teoria da estruturação em uma empresa têxtil. Revista de Administração da Universidade de São Paulo, 47(4), pp. 653-670. DOI: 10.5700/rausp1065

Boland, R. J., Jr. (1993). Accounting and the interpretive act. Accounting, Organizations and Society, 18(2), pp. 125-146.

Burchell, S., Clubb, C., \& Hopwood, A. G. (1985). Accounting in its social context: towards a history of value added in the United Kingdom. Accounting, organizations and Society, 10(4), pp. 381-413.

Clegg, S., (1979). The Theory of Power and Organizations, London, Routledge \& Kegan Paul.

Coad, A. F., \& Herbert, I. P. (2009). Back to the future: new potential for structuration theory in management accounting research? Management Accounting Research 20(3), pp. 177-192

Coad, A. F., \& Glyptis, L. G. (2014). Structuration: a position-practice perspective and an illustrative study. Critical Perspectives on Accounting 25(2), pp. 142-161

Cohen, J. (1989). Deliberation and Democratic Legitimacy, in The Good Polity: Narrative Analysis of the State, edited by Alan Hamlin and Philip Pettit. New York: Basil Blackwell.

Collier, P. M. (2001). The power of accounting: a field study of local financial management in a police force. Management Accounting Research, 12(4), pp. 465-486.

Conrad, L. (2005). A structuration analysis of accounting systems and systems of accountability in the privatised gas industry. Critical perspectives on accounting, 16(1), pp. 1-26. DOI:10.1016/S10452354(02)00212-5

Cosenza, J. P., Teixeira Filho, A. C., \& Lopes, R. de S. S. A. (2012). Reflexão Sobre Relações Entre Poder e Contabilidade. Contabilidade, Gestão e Governança, 15(2).

Cowton, C. J., \& Dopson, S. (2002). Foucault's prison? Management control in an automotive distributor. Management accounting research, 13(2), pp. 191-213. DOI:10.1006/mare.2001.0173

Englund, H., Gerdin, J., \& Burns, J. (2011). 25 years of Giddens in accounting research: achievements, limitations and the future. Accounting, Organizations and Society, 36(8), pp. 494-513. DOI:10.1016/j. aos.2011.10.001

Gadamer, H. G. (1976). Philosophical hermeneutics. Califórnia: University California Press.

Giddens, A. (2009). A constituição da sociedade. Tradução: Álvaro Cabral. (3a ed.). São Paulo: Editora WMF Martins Fontes.

Granlund, M., Lukka, K., \& Mouritsen, J. (1998). Institutionalised justification of corporate action: internationalisation and the EU in corporate reports. Scandinavian Journal of Management, 14(4), pp. 433-458. DOI: org/10.1016/S0956-5221(97)00046-8

Granlund, M. (2002). Changing legitimate discourse: a case study. Scandinavian Journal of Management, 18(3), pp. 365-391. 
Guarido, E. R., Fo \& Costa, M. C. (2012). Contabilidade e institucionalismo organizacional: fundamentos e implicações. Revista Contabilidade e Controladoria-RCßC, 4(1).

Guo, X., Zhang, N., \& Chen, G. (2009). Adoption and penetration of e-government systems: conceptual model and case analysis based on structuration theory. In Proceedings of the Digital Media Exposition.

Hossain, M. D., Moon, J., Kim, J. K., \& Choe, Y. C. (2011). Impacts of organizational assimilation of e-government systems on business value creation: A structuration theory approach. Electronic Commerce Research and Applications, 10(5), pp. 576-594. DOI: 10.1016/j.elerap.2010.12.003

Hoskin, K. (1998). Examining accounts and accounting for management: inverting understandings of 'the economic', in A. McKinlay, K. Starkey (eds), Foucault, Management and Organization Theory: from Panopticon to Technologies of Self, London, Sage, 92-110. DOI: http://dx.doi. org/10.4135/9781446221686

Jack, L. (2005). Stocks of knowledge, simplification and unintended consequences: the persistence of post-war accounting practices in UK agriculture. Management Accounting Research, 16(1), pp. 59-79. DOI: 10.1016/j.mar.2004.08.003

Jack, L. (2007). Accounting, post-productivism and corporate power in UK food and agriculture. Critical Perspectives on Accounting, 18(8), pp. 905-931.

Jack, L. \& Kholeif, A. (2007). Introducing Strong Structuration Theory for Informing Qualitative Case Studies in Organization, Management and Accounting Research. Qualitative Research in Organizations and Management: An International Journal 2(3), pp. 208- 225. DOI: org/10.1108/17465640710835364

Jack, L. \& Kholeif, A. (2008). Enterprise resource planning and a contest to limit the role of management accountants: a strong structuration perspective. Accounting Forum 32(1), pp. 30-45. DOI: 10.1016/j. accfor.2007.11.003

Jayasinghe, K., \& Thomas, D. (2009). The preservation of indigenous accounting systems in a subaltern community. Accounting, Auditing \& Accountability Journal, 22(3), pp. 351-378. DOI: 10.1108/09513570910945651

Jones, C. T., \& Dugdale, D. (2001). The concept of an accounting regime. Critical Perspectives on Accounting, 12(1), pp. 35-63.

Lawrenson, D. M. (1992). Britain's railways: The predominance of engineering over accountancy during the inter-war period. Critical Perspectives on Accounting, 3(1), pp. 45-60. DOI: 10.1016/10452354(92)90014-I

Lawrence, S., Alam, M., Northcott, D., \& Lowe, T. (1997). Accounting systems and systems of accountability in the New Zealand health sector. Accounting, Auditing \& Accountability Journal, 10(5), pp. 665-683. DOI: org/10.1108/09513579710194036

Lowe, T., Puxty, T., \& Chua, W. F. (Eds.). (1989). Critical perspectives in management control. Macmillan Press.

Luhmann, N. (1979). Trust and power. Chichester: Wiley.

Macintosh, N. B., \& Scapens, R. W. (1990). Structuration theory in management accounting. Accounting, Organizations and Society, 15(5), pp. 455-477. DOI: 10.1016/0361-3682(90)90028-S

Macintosh, N. B. (1995). The ethics of profit manipulation: a dialectic of control analysis. Critical Perspectives on Accounting, 6(4), pp. 289-315.

Neimark, M. \& Tinker, A. M. (1986). The social construction of management control systems. Accounting Organizations and Society. 11(4/5), pp. 369-395. DOI: 10.1016/0361-3682(86)90008-5 
Pfeffer, J. (1992). Managing with Power: Politics and Influence in Organizations, Boston, Harvard Business School Press.

Ribeiro, S. M. R. (2010). Fortalecimento das instituições de controle na APF do Brasil. Congresso CONSAD de Gestão Pública. Brasília, DF, Brasil, 3.

Roberts, J. (1990). Strategy and accounting in a UK conglomerate. Accounting, Organizations and Society, 15(1), pp. 107-126. DOI: 10.1016/j.aos.2006.08.001

Rodrigues, E. M. T. (2008). A interação entre sistemas de informação e o trabalho no setor bancário no Brasil: uma estruturalista. Tese de Doutorado. FGV/EBAPE - Escola Brasileira de Administração Pública e de Empresas, Rio de Janeiro, RJ, Brasil. Recuperado de http://bibliotecadigital.fgv.br/dspace/ bitstream/handle/10438/4192/TESE\%20Revisada.pdf?sequence=1\&isAllowed=y

Rosenbaum, H. (1993). Information Use Environments and Structuration: Towards an Integration of Taylor and Giddens. Proceedings of the ASIS annual meetin. pp. 235-45.

Santos, A. R. dos (2008). Diagnóstico institucional dos fatores que concorrem para o isomorfismo das práticas de contabilidade gerencial utilizadas pelas organizações do setor elétrico brasileiro. Dissertação de Mestrado da Universidade Federal do Paraná, Curitiba, PR, Brasil. Recuperado de http://www. ppgcontabilidade.ufpr.br/system/files/documentos/Disserta coes/D001.pdf

Saravanamuthu, K., \& Tinker, T. (2003). Politics of managing: the dialectic of control. Accounting, Organizations and Society, 28(1), pp. 37-64.

Scapens, R. W., \& Macintosh, N. B. (1996). Structure and agency in management accounting research: a response to Boland's interpretive act. Accounting, Organizations and Society, 21(7), pp. 675-690. DOI: $10.1016 / 0361-3682(95) 00049-6$

Scapens, R. W.; \& Roberts, J. (1993). Accounting and control: a case study of resistance to accounting change. Management Accounting Research, v. 4, n. 1, p. 1-32, 1993. DOI: 10.1006/mare.1993.1001

Scott, W. R. (2001). Institutions and Organizations. (2 ed.) London, Sage Publications,.

Silva, C. L. M. da, \& Fonseca, V. S. da (1993). Estruturação da estrutura organizacional: o caso de uma empresa familiar. Organizações \& Sociedade, 1(1), pp. 42-71.

Tavares, E. (2012). Fatores influentes e tipos de uso emergentes da construção social de sistemas de informação no setor bancário. Organizações \& Sociedade, 19(62).

Uddin, S., \& Tsamenyi, M. (2005). Public sector reforms and the public interest: a case study of accounting control changes and performance monitoring in a Ghanaian state-owned enterprise. Accounting, Auditing \& Accountability Journal, 18(5), pp. 648-674. DOI: 10.1108/09513570510620493

Wanderley, C. de A., \& Cullen, J. (2012). A Case of Management Accounting Change: the Political and Social Dynamics. Revista Contabilidade \& Finanças, 23(60), pp. 161-172.

Walter, S. A., Cruz, A. P. C. D., Espejo, M. M. D. S. B., \& Gassner, F. P. (2009). Uma análise da evolução do campo de ensino e pesquisa em contabilidade sob a perspectiva de redes. Revista Universo Contábil, 5(4), pp. 76-93.

Weber, M. (1947). The theory of economic and social organization. Trans. AM Henderson and Talcott Parsons. New York: Oxford University Press. 